\title{
Effectiveness of a standardized footbath protocol for prevention of digital dermatitis
}

\author{
L. Solano, ${ }^{1}$ H. W. Barkema, C. Pickel, and K. Orsel \\ Department of Production Animal Health, University of Calgary, Calgary, Alberta, Canada, T2N 4N1
}

\begin{abstract}
A footbath is the most common herd-level approach to control digital dermatitis (DD) in intensive dairy farming. However, wide variation in footbath design and protocols suggests a gap between evidence-based management practices and on-farm implementation. The objective was to evaluate effectiveness of a standardized footbath protocol in decreasing prevalence of active DD lesions in lactating dairy cattle. The protocol was based on current scientific literature, including footbath design and management. The M-stage classification system was used to score DD lesions. Scores were also combined into a simplified scoring system: no lesions (M0), active lesions (M1, M2, and M4.1), and chronic lesions (M3 and M4). A controlled intervention trial was conducted on 9 farms over 22 wk. Each farm served as its own control with data collected for $10 \mathrm{wk}$ before and $12 \mathrm{wk}$ after intervention. A total of 1,978 lactating cattle were assessed biweekly for DD lesions and leg cleanliness in the milking parlor. Lactating cattle were also inspected in the trimming chute at 3 time points: start, intervention, and end of trial. Intervention consisted of implementing an automated footbath that measured $3 \mathrm{~m}$ long, $0.50 \mathrm{~m}$ wide, held a fluid depth of $0.15 \mathrm{~m}$, along with a weekly footbath protocol using $5 \% \mathrm{CuSO}_{4}$ for 4 consecutive milkings, with footbath content replaced at a maximum of 200 cow passes. Multilevel logistic regression models for repeated measures were used to evaluate effects of the standardized footbath protocol in preventing active DD lesions. For the purpose of analysis, farms' within-herd prevalence of active DD lesions (at baseline) was assessed and categorized as low $(<15 \%)$ or high $(\geq 15 \%)$. Farms with low or high within-herd prevalence of active DD lesions at trial outset had a mean cow-level prevalence of active DD lesions of $8 \%$ (range, 2 to 13) and $31 \%$ (range, 18 to 43), respectively. At milking parlor inspections, apparent prevalence of active DD lesions
\end{abstract}

Received May 16, 2016.

Accepted October 7, 2016.

${ }^{1}$ Corresponding author: laurasolanoquesada@gmail.com decreased from the time of footbath intervention, but this effect interacted with the farms' baseline prevalence of active DD lesions. In that regard, on farms with high prevalence of active DD at baseline, apparent prevalence of active DD lesions decreased after intervention, whereas on farms with low prevalence of active DD at baseline, apparent prevalence of active DD lesions did not change. At the cow level, poor leg cleanliness was associated with higher prevalence of active DD lesions. At trimming chute inspections, prevalence of active DD lesions decreased from start to the end of the trial (22 and 14\%, respectively); concurrently, prevalence of feet with no DD lesions (M0) increased (39 and 48\%). We concluded that on farms with high DD prevalence, implementation of proper footbath design and improvement of footbathing management will decrease prevalence of active DD lesions and increase prevalence of feet without DD lesions. In addition, improving cow cleanliness will further result in control of active DD lesions.

Key words: automatic footbath, intervention study, prevention, lameness, digital dermatitis

\section{INTRODUCTION}

Digital dermatitis (DD) is a widespread infectious foot lesion in cattle that typically causes painful ulcerative lesions (Cheli and Mortellaro, 1974; Read and Walker, 1998). Digital dermatitis has become endemic in intensively managed dairy systems (Blowey, 2005), affecting 70 to $95 \%$ of North American dairy farms (Cramer et al., 2008; USDA, 2009; Solano et al., 2016). The prevalence of DD is higher in cows managed in confinement housing than in pasture-based systems, with the highest within-herd prevalence reported in freestalls (22 to $23 \%$ in Canada; Cramer et al., 2008; Solano et al., 2016) compared with tiestalls (9 to $15 \%$ in Canada; Cramer et al., 2008; Solano et al., 2016) and deep-bedded straw yards (4 to $9 \%$; Somers et al., 2003; Solano et al., 2016). In pastured-based systems in New Zealand and Chile, the prevalence of DD was approximately 7\% (Chesterton et al., 2008; Tadich et al., 2010). 
Digital dermatitis lesions can be painful and persist for long intervals, with recurrent outbreaks (Döpfer, 2009; Bruijnis et al., 2012), and can cause changes in foot conformation that favor occurrence of other infectious foot lesions (Gomez et al., 2015), resulting in reduced animal welfare. Furthermore, DD has substantial financial implications associated with decreased milk production, increased risk for culling, and increased treatment costs (Cha et al., 2010; Ettema et al., 2010; Relun et al., 2013a), accounting for the highest cost among all foot disorders due to its high incidence and prevalence (Bruijnis et al., 2010).

Digital dermatitis is considered a multifactorial and polybacterial disease, with treponemes consistently isolated from DD lesions (Döpfer et al., 2012c; Gomez et al., 2012; Krull et al., 2016), whereas host susceptibility (Scholey et al., 2010), poor cleanliness, and wet conditions (Rodríguez-Lainz et al., 1996; Relun et al., 2013b) are implicated as risk factors. However, the etiology and pathogenesis of DD are not fully elucidated, contributing to challenges in its control.

Several control strategies have been recommended, including maintaining a clean, dry environment, individual topical treatment of affected cows, and herd-level strategies, including footbathing (Laven and Logue, 2006; Nuss, 2006; Döpfer et al., 2012b). Early detection and prompt topical treatment of active DD lesions improve cure rates and reduce spread of infection; furthermore, an effective footbath program can prevent occurrence of active lesions (Döpfer et al., 2012b). Footbaths are a common preventative approach due to the labor involved in treating large numbers of affected cows (Laven and Logue, 2006), along with strong evidence from intervention trials supporting footbath efficacy in reducing DD prevalence compared with negative controls (Speijers et al., 2010; Relun et al., 2012; Fjeldaas et al., 2014). However, there is a wide variation in onfarm practices related to footbath management (Cook et al., 2012; Relun et al., 2013c; Solano et al., 2015). In a recent study involving 81 freestall barns in Alberta, $95 \%$ of farms used a footbath regularly; nevertheless, no 2 farms had the same protocol, and only $3 \%$ of farms met all criteria regarding suggested footbath dimensions. A total of 22 chemical product combinations were recorded, with a range of 1 to 4 chemicals used per farm on a frequency of 0 to $7 \mathrm{~d} /$ wk (Solano et al., 2013).

These findings suggest a gap between evidence-based management practices and on-farm implementation of footbaths. Most studies have compared chemicals and concentrations used in footbaths, but there is a paucity of research focused on standardization and optimization of footbathing practices for DD prevention (Cook et al., 2012; Potterton et al., 2012). One study assessed effects of various footbath dimensions on number of foot immersions and recommended long $(3 \mathrm{~m})$ and deep $(0.28 \mathrm{~cm})$ footbaths to optimize chemical delivery to cows' feet (Cook et al., 2012). However, in that study, effects of various footbath dimensions on DD were not estimated. Logue et al. (2012) compared a 2.2 versus 4.4 $\mathrm{m}$ long footbath and reported an improvement of DD in herds with longer footbaths, although not necessarily a decrease in lesion prevalence. The objective of the present study was therefore to evaluate effectiveness of a standardized footbath protocol in decreasing prevalence of active DD lesions. The protocol was based on current scientific literature, including footbath design and management.

\section{MATERIALS AND METHODS}

\section{Farm and Cow Selection}

A total of 9 freestall dairy farms in Alberta, Canada, participated in the study. The farm and cow selection process was described in detail by Solano et al. (2017). In short, eligible farms were clients of 2 hoof trimmers. To ensure participants were representative of Alberta dairies, farms were selected that had freestall housing systems with no access to pasture, a herd size $\geq 90$ Holstein-Friesian lactating cows, and routine footbathing of lactating cows (Table 1). To ensure farms were endemically infected with DD, selected farms had $\geq 10 \%$ DD prevalence (regardless of M-stage) based on hoof trimming records from the past $2 \mathrm{yr}$. To decrease potential bias introduced by the use of various footbath chemicals, all farms were required to use copper sulfate $\left(\mathrm{CuSO}_{4}\right)$, as it is the most common chemical used in footbaths in Canada (Solano et al., 2015; Table 2). Participating farmers gave consent to share their foot trimming and milk production records provided by hoof trimmers and CanWest DHI (Guelph, ON, Canada), respectively. Individual data on parity, DIM, and test-day milk production (measured at the most recent monthly milk recording after data collection) for sampled cows were obtained from CanWest DHI. Data on the 9 farms were collected between November 2013 and June 2014 by 2 trained observers and the first author. All methods were approved by the Animal Care Committee (AC13-0082) and Research Ethics Board (REB13-0599) of the University of Calgary.

\section{Study Design}

A controlled intervention trial was conducted wherein each farm served as its own control, with data collected before and after intervention. Selection of farms as their 
own control rather than a comparison with a subgroup of negative control farms was decided after careful examination of factors related to seasonality, power, and variability of management practices among farms. All lactating cows were assessed biweekly for DD lesions in the milking parlor for 6 mo (Figure 1). The 9 farms were visited 6 times before and 6 times after intervention with the footbath protocol. In addition, the entire lactating herd was inspected in the trimming chute at 3 time points: start of data collection (wk 1), the day of intervention (wk 10), and end of data collection (wk 22 ). Before intervention, no changes were made to the farms' original footbath and DD protocols. For ethical and welfare reasons, farmers were expected to continue their routine individual treatments for DD (Table 1) and were asked to record cow identification, date, and nature of treatment.

\section{General Management}

A questionnaire was administered on every farm. The questionnaire was pretested on 2 farms to evaluate whether it was understood easily and interpreted correctly. Thereafter, the questionnaire was adapted and improved where necessary. Questions were either openended (e.g., "Describe the footbath chemical(s) you use, in what concentration and frequency"; Table 2) or closed ended (e.g., "Is the amount of footbath chemical measured/weighed before mixing?"; scale of answer: always, sometimes, or never). Detailed information was collected from the questionnaire on the frequency of use (times/wk), frequency of changing solutions, chemicals used and their concentrations. Farms' original footbaths were measured (length, depth, and width) for every footbath used. In addition, data on DD monitoring and treatment, along with hoof trimming routines, were collected.

\section{Footbath Intervention}

Footbath. A computerized automated footbath was implemented on all farms, 3 mo after the start of data collection. Stainless steel, split walk-through footbaths were used, consisting of 2 baths separated by a grate (Boumatic, Chinook Dairy Service, Lethbridge, AB, Canada; Figure 2). The dimensions were selected based on recommendations from Cook et al. (2012) and Shearer and Van Amstel (2013); each bath was $3 \mathrm{~m}$ long, $0.25 \mathrm{~m}$ wide, and held a fluid depth of $0.15 \mathrm{~m}$ $(9.8 \mathrm{ft} \times 9.8 \mathrm{in} \times 5.9 \mathrm{in})$, for a combined volume of 225 L. Footbaths had a center grate, rubber flooring, side walls, and a flush door, to prevent manure contamination and ensure good grip, immersion of feet, and automatic flushing, respectively. One farm opted to have a 
SOLANO ET AL.

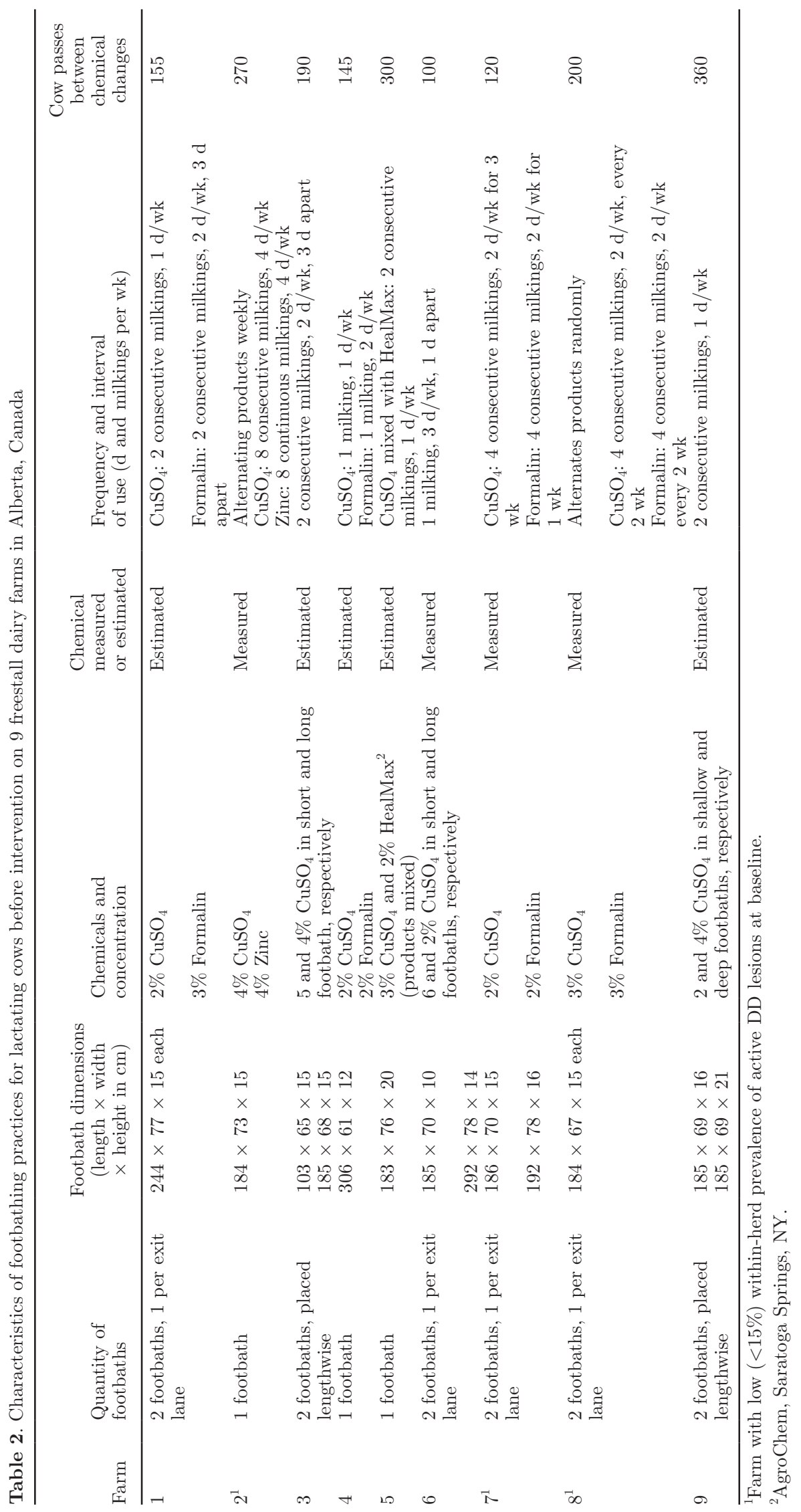


Trim chute inspections

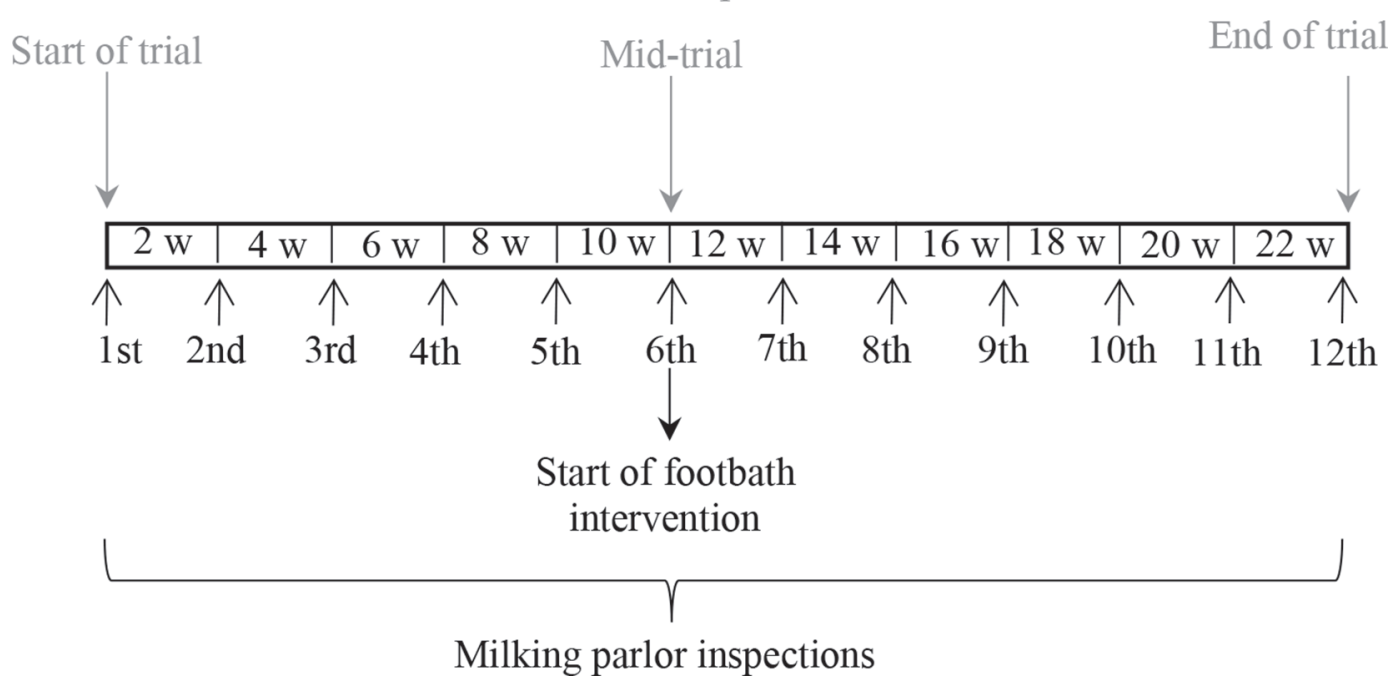

Figure 1. Timeline of trial, showing digital dermatitis inspections at milking parlor (every $2 \mathrm{wk}$ ) and at trimming chute (start, middle, and end of trial).

footbath without the grate; therefore; the width on this farm's footbath was $0.75 \mathrm{~m}$ and it held a volume of 338 L. All footbaths were custom made to fit the farms' exit alley dimensions. The footbath system had a liquid and powder dispenser with an auger to store the $\mathrm{CuSO}_{4}$ and a mixing chamber where it was automatically mixed before being dispensed into the footbath.

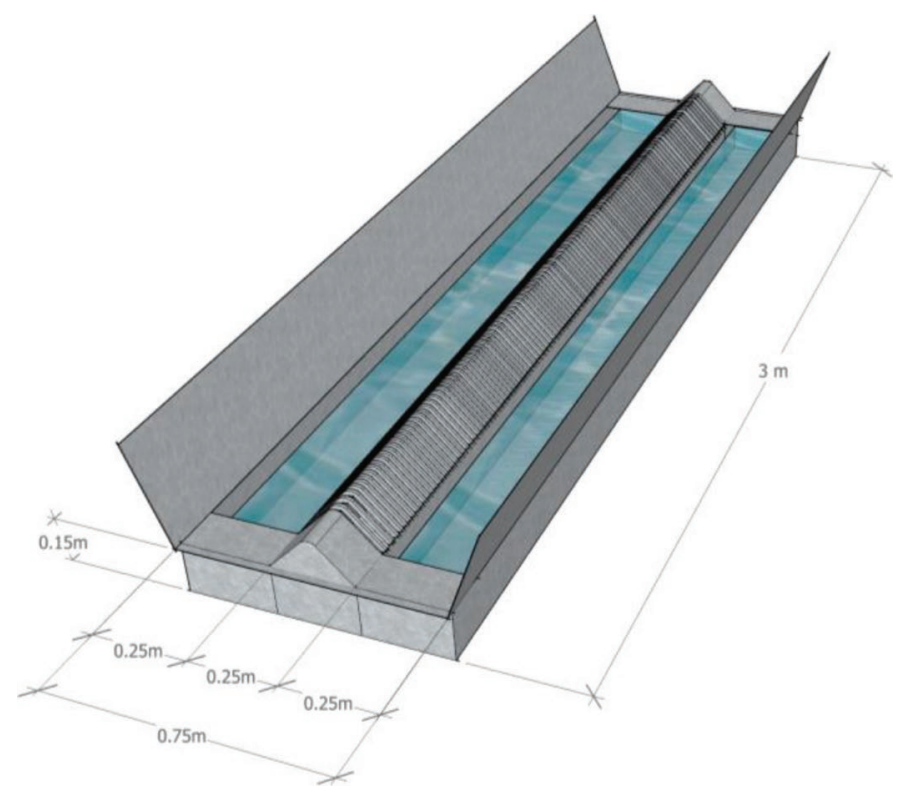

Figure 2. Computerized automated footbath with dimensions based on literature recommendations implemented on 9 dairy farms. Color version available online.
On all farms, footbath software was programmed to prepare a $5 \% \mathrm{CuSO}_{4}$ solution and to fill, flush, and empty the chemical. The system's software was installed on a damage-resistant touch screen with an operating system where time, day, and frequency of use could be adjusted. For the study period, a secure password, only known by the authors, was assigned to all footbath systems so that the assigned protocol could not be modified. In addition, the software offered memory access through a USB port to retrieve data on the chemical, date, and time of footbathing cycles, which aided in evaluating footbath function between visits. Footbaths were located in the exit lanes, as far away from the milking parlor as farm design allowed. This was to minimize both interruption of cow flow while exiting the milking parlor and manure contamination. Farmers did not have to manually operate nor prepare the footbath, but they were responsible for checking proper functioning of the footbath door drainage, and that sufficient $\mathrm{CuSO}_{4}$ was stored in the dispenser. Farmers were advised to immediately notify the researchers and the footbath company of any malfunctions.

Standardized Footbath Protocol. Before installation of the standard footbath, all farms used $\mathrm{CuSO}_{4}$ as part of their original footbath protocol (Table 2). After implementation of the protocol, all farms solely used $\mathrm{CuSO}_{4}$. The standardized protocol consisted of weekly use of $\mathrm{CuSO}_{4}$ at a $5 \%$ concentration for 4 consecutive milkings over 2 consecutive days (Speijers et al., 2010; Relun et al., 2012; Speijers et al., 2012). Farmers were asked to pre-wash cows' feet in the milking parlor before footbathing. The footbath content was automatically 
flushed and replaced at no more than every 200 cow passes (Cook, 2006) or after $24 \mathrm{~h}$ if $<200$ cows passed through the footbath. The footbath was also cleaned using an automated system between each use.

Follow-Up. At each of the 6 visits that followed the footbath intervention, researchers verified: (1) compliance with footbath protocol by checking the software's memory data and confirming with the farmer (i.e., proper functioning of footbath functioning, flushing footbath contents, and refilling as required); (2) compliance with other management practices (i.e., cleaning cows' feet with water before footbath, individual treatments); (3) manure scraper function; and (4) purchase of cattle from other farms.

\section{Assessment of DD and Leg Cleanliness}

Training. Training of observers has been described in detail by Solano et al. (2017). Briefly, 2 observers were trained by the first author to identify and score DD and leg cleanliness in various settings, using 40 photographs and live in the milking parlor $(\mathrm{n}=110$ cows) and trimming chute ( $\mathrm{n}=40$ cows). A mid-way check (12 wk after initial data collection) using different photographs was done to maintain agreement throughout the study. Interobserver agreement for scoring DD and leg cleanliness in various settings was substantial to almost perfect (percentage of agreement $\geq 82 \%$; kappa $>0.74$; Solano et al., 2017).

Digital Dermatitis. Lactating cows were scored for DD every $2 \mathrm{wk}$ in the milking parlor. Inspection of DD in the milking parlor has been described in detail (Solano et al., 2017). Briefly, cows' feet were washed with water from a hose before examination. Feet were inspected using a mirror (glued to a plastic kitchen spatula) and a headlamp. A 5-point scale according to Döpfer et al. (1997) and Berry et al. (2012), known as the M-stage scoring system, was used to score DD lesions (Table 3). The M-stage scoring system, based on visual observation, characterizes various clinical stages of DD over the course of the disease, enabling detection of transitions between active and chronic stages (Döpfer et al., 2012a). Shortly, lesions were classified as M0 if skin was normal with no sign compatible with a pre-existing lesion; as M1 and M4.1 if an active DD lesion $<2 \mathrm{~cm}$ was observed surrounded by healthy skin or by dyskeratotic or proliferative skin alteration, respectively; as M2 if an active lesion $\geq 2 \mathrm{~cm}$ was present; as M4 (chronic) if a hyperkeratotic or proliferative growth was observed; and as M3 (healing stage) if the lesions were a dry brown and scab-like tissue. Pictures of each M-stage are included in the book developed by Zinpro International Bovine Lameness Committee (2014). Additionally, hind feet of all lactating cows were inspected for DD in the trimming chute at 3 time points, 10 and 12 wk apart. Cow's feet were thoroughly cleaned with paper towels before scoring in the trimming chute. For ethical and welfare reasons, cows with M2 lesions were treated according to the hoof trimmers' standardized protocol. The protocol consisted of (1) cleaning the lesion area with paper towel; (2) pouring 2 scoops (approximately $15 \mathrm{~g}$, scoop provided) of tetracycline powder (Tetracycline 250, Vétoquinol, Lavaltrie, QC, Canada) on top of the lesion; (3) covering with a disinfectant agent (Dragonhyde Putty, T-Hexx Animal Health, Branchburg, NJ) applied with a small, flat wooden (popsicle) stick; and (4) wrapping loosely with Vetwrap (Coflex).

Leg Cleanliness. Along with DD inspection, cows were scored for leg cleanliness every 2 wk in the milking parlor, using the scoring system adapted from Cook (2006) and described by Solano et al. (2015). Namely, cleanliness on the lateral lower hind legs, from the coronary band to the middle of the tarsal joint, was recorded using a 0 to 3 scale according to the degree of contamination: $0=$ fresh manure for $<50 \%$ of the area;

Table 3. M-stage scoring system for digital dermatitis (DD) lesions

\begin{tabular}{|c|c|c|c|}
\hline DD score ${ }^{1}$ & M-stage description ${ }^{1}$ & Progression $^{2}$ & $\begin{array}{l}\text { Simplified scoring } \\
\text { system }\end{array}$ \\
\hline$\overline{\mathrm{M} 0}$ & Normal skin. No signs of dermatitis. & M1 & No lesion \\
\hline M1 & $\begin{array}{l}\text { Small ( }<2 \mathrm{~cm} \text { across) focal active stage, circumscribed, red-gray surface. Generally } \\
\text { not painful. }\end{array}$ & M0, M2, M4 & Active lesion \\
\hline M2 & $\begin{array}{l}\text { Large ( }>2 \mathrm{~cm} \text { across) ulcerative active stage, bright red or red-gray surface. Can be } \\
\text { painful. }\end{array}$ & M3, M4.1 & Active lesion \\
\hline M3 & $\begin{array}{l}\text { Healing stage. Typically occurs within } 2 \mathrm{~d} \text { following treatment of M2 lesion. Dry, } \\
\text { brown, scab-like surface. Not painful. }\end{array}$ & M0, M2, M4 & Chronic lesion \\
\hline M4.1 & Chronically recurring stage with small active, painful M1 focus. & $\mathrm{M} 2, \mathrm{M} 4$ & Active lesion \\
\hline
\end{tabular}


$1=$ fresh manure for $>50 \%$ of the area; $2=$ dried caked and fresh manure for $>50 \%$ of the area; and $3=$ entire area with dried caked manure.

\section{Statistical Analyses}

Data were entered into Microsoft Access (Microsoft Corp., Redmond, WA), and statistical analyses were performed using Stata 13.1 (StataCorp, 2013, College Station, TX). For all analyses, a $P$-value $<0.05$ was considered significant. The foot within a cow was considered the statistical unit. All descriptive analyses were calculated using the $5 \mathrm{M}$-stages and also using a simplified scoring system: no lesions (M0), active lesions (M2 and M4.1 were merged), and chronic lesions (M3 and M4 were merged). Merging or excluding M-stages was based on findings by Solano et al. (2017) that sensitivity was low and misclassification was common for detecting M1 and M3 lesions in the milking parlor compared with the trimming chute as the gold standard. In that regard, M1 lesions were excluded from analyses due to low frequency, common misclassification with M0, and low sensitivity (6\%). In addition, M3 was merged with M4 lesions due to common misclassification $(61 \%)$ of M3 lesions as M4 lesions. Furthermore, combining M3 and M4 into 1 category can be justified by the infectiousness relevance and clinical implications of the stages (Relun et al., 2011). If $>1$ DD lesion was observed on the same foot, analysis was done using the most clinically relevant M-stage, according to the order: M2 > M4.1 > M1 > M4 > M3 (Relun et al., 2011; Gomez et al., 2014; Solano et al., 2017).

The difference in the proportion of lesions at start, middle (intervention), and end of the trial was assessed using McNemar's test. Leg cleanliness was collapsed into clean (score 0 and 1 ) and dirty (score 2 and 3 ) due to low frequency of 2 categories. If 2 predictors were highly correlated (e.g., DIM and milk production; $|\mathrm{r}|$ $\geq 0.70$ ), the one with the fewest missing observations was chosen.

Multilevel logistic regression models for repeated measures were used to evaluate effects of the standardized footbath protocol in prevalence of active DD lesions. Active DD lesions (M2 and M4.1 combined) at foot level were the outcome of interest. Univariable analyses were performed to assess associations between outcome and covariates. Farm was forced into the final regression model as a fixed effect and cow as a random effect. Baseline prevalence of active lesions was included in the analysis as a herd-level variable. Cow- and herdlevel variables significant at $P \leq 0.05$ were retained in the final model for each outcome. Additionally, if confounding was present (i.e., removal of any variable resulted in a $30 \%$ change in the estimate of any other significant predictor), that variable was also retained in the final model. Predictor variables considered included week of trial, baseline footbath protocol, parity, DIM, and leg cleanliness. Two-way biologically relevant interactions (e.g., parity and DIM; parity and leg cleanliness) were tested among the significant predictors in the main effects model, but none was retained $(P>$ 0.05 in all cases). Whenever the term prevalence is used in relation to data from the milking parlor and trimming chute inspections, it refers to apparent and true prevalence, respectively.

\section{RESULTS}

\section{Farms and Footbath Practices}

Average herd size was 152 lactating cows (range, 87 to 209), with mean daily milk production of $33 \mathrm{~kg} /$ cow and parity of 2 (Table 1). Footbath design and footbathing practices before footbath intervention varied greatly among farms (Table 2). Footbaths had a median length of $192 \mathrm{~cm}$ (range, 183 to 370) and a mean depth of $15 \mathrm{~cm}$ (range, 10 to 21). On average, footbath contents were replaced every 204 cow passes (range, 100 to 360$)$. The majority of farms $(n=6)$ used a combination of 2 chemicals (mostly with formalin), and chemical concentration was accurately determined on 4 farms who measured/weighed the product before mixing. Within-herd prevalence of active DD lesions (at baseline) was considered low $(<15 \%)$ on 3 of 9 farms (Table 1).

All farms had an individual DD treatment protocol in place (Table 1). However, only 10 cows on 4 farms were treated by the farmer during the study period; of these, 6 cows on 3 farms were treated after the footbath intervention. A total of $8.8,10.2$, and $3.6 \%$ of cows received topical treatments during trimming chute inspections at the start, mid, and end of the trial, respectively. None of the farms complied after intervention with prewashing cows' feet before footbathing.

\section{Prevalence of Digital Dermatitis Lesions}

A total of 30,672 observations on 1,978 lactating cows (3,956 feet) were collected throughout the study period. At baseline, apparent within-herd prevalence of cows with DD occurring in $\geq 1$ foot was $69 \%$ (range, 15 to 86) and apparent prevalence of cows with active DD lesions was 23\% (range, 3 to 43; Table 1). On farms with low or high within-herd prevalence of active DD lesions at baseline, apparent within-herd prevalence of cows with active DD lesions was $8 \%$ (range, 3 to 13 ) and $31 \%$ 
Table 4. Prevalence (\%) of each digital dermatitis M-stage identified at trimming chute inspection on 3,956 feet at start of data collection, intervention, and end of data collection

\begin{tabular}{|c|c|c|c|c|c|c|c|c|c|c|c|c|}
\hline \multirow[b]{2}{*}{ Time point inspection } & \multicolumn{6}{|c|}{ Trimming chute inspection } & \multicolumn{6}{|c|}{ Milking parlor inspection ${ }^{1}$} \\
\hline & M0 & M1 & M2 & M3 & M4 & M4.1 & M0 & M1 & M2 & M3 & M4 & M4.1 \\
\hline Intervention (wk 10) & $41.6^{\mathrm{a}}$ & $5.0^{\mathrm{b}}$ & $10.3^{\mathrm{a}}$ & $0.0^{\mathrm{a}}$ & $27.7^{\mathrm{b}}$ & $15.4^{\mathrm{b}}$ & $45.1^{\mathrm{b}}$ & $0.4^{\mathrm{a}}$ & $5.5^{\mathrm{b}}$ & $0.2^{\mathrm{b}}$ & $42.3^{\mathrm{b}}$ & $6.5^{\mathrm{b}}$ \\
\hline End (wk 22) & $47.9^{\mathrm{b}}$ & $1.9^{\mathrm{c}}$ & $3.6^{\mathrm{b}}$ & $0.3^{\mathrm{a}}$ & $35.8^{\mathrm{a}}$ & $10.5^{\mathrm{c}}$ & $47.4^{\mathrm{b}}$ & $0.1^{\mathrm{a}}$ & $2.6^{\mathrm{c}}$ & $0.1^{\mathrm{b}}$ & $46.0^{\mathrm{c}}$ & $3.8^{\mathrm{c}}$ \\
\hline
\end{tabular}

${ }^{\mathrm{a}-\mathrm{c}}$ Within a column, prevalence without a common superscript differed $(P<0.05)$.

${ }^{1}$ Apparent prevalence identified in the milking parlor.

(range, 20 to 43), respectively. Of all cows with DD at baseline, $65 \%$ were affected with M4 lesions, and $33 \%$ were affected with active DD lesions (Table 1).

At trimming chute inspections, prevalence of feet with no DD lesions (M0) increased from start to the end of the trial (39 and 48\%, respectively), whereas prevalence of active DD lesions decreased (22 and 14\%; Table 4). This same trend was detected in the milking parlor, but apparent prevalence of M4 lesions was higher at milking parlor inspections compared with the trimming chute. Conversely, prevalence of M4.1 lesions was higher at trimming chute inspections compared with the milking parlor. Presence of M1 lesions was infrequently detected in the milking parlor (apparent prevalence $<1 \%$ ), but at trimming chute inspections, a decrease in the prevalence of M1 lesions was detected at the end of the trial (Table 4). In addition, prevalence of active DD lesions decreased by almost $50 \%$ from the time of footbath intervention to the end of the trial as detected in both trimming chute inspections (26 and $14 \%$, respectively) and milking parlor inspections (12 and $6 \%$, respectively).

Prevalence of active DD lesions decreased from the time of footbath intervention, but this effect interacted with the farms' baseline within-herd prevalence of active DD lesions. In that regard, on farms with high prevalence at baseline, prevalence of active DD lesions decreased after intervention, whereas on farms with low prevalence at baseline, prevalence of active DD lesions did not change $(P<0.001$; Table 5 ; Figure 3$)$. Prevalence and distribution of M-stages was similar at the end of the trial between farms with low and high prevalence of active DD lesions before the footbath intervention (Figure 3). Specific results per farm before and after footbath intervention are included as Supplemental Figure S1 (https://doi.org/10.3168/jds.2016-11464).

At the cow level, primiparous cows had a higher apparent prevalence of active DD lesions compared with cows with parity $\geq 3$ (Table 5 ). Poor leg cleanliness was associated with higher apparent prevalence of active DD lesions, but this association was confounded by farm.

\section{DISCUSSION}

In this study, prevalence of active DD lesions was reduced considerably in herds with high DD prevalence at baseline by implementing a standardized footbath protocol based on current science-based recommendations on footbath design and management. In addition, the use of this standardized footbath protocol increased prevalence of cows without DD lesions. Prevalence of active DD lesions was also affected by individual-cow factors, namely leg cleanliness and parity.

In herds with high baseline prevalence of active DD, a pronounced decrease was found in active DD lesions and an increase in chronic DD lesions from wk 10 to 12 (Figure 3). The majority of M2 lesions transition to a chronic or healed stage $2 \mathrm{wk}$ after topical treatment (Holzhauer et al., 2011). This decrease, which was also observed to a lesser extent after the treatment at wk 0 in both herds with high and low prevalence of active DD lesions, was therefore likely due to topical treatment of M2 lesions during trimming chute inspections and not due to the footbath intervention. Despite that, 9 and $10 \%$ of cows were treated topically during trimming inspections at the start and at intervention, respectively, although the trend was different for prevalence of active DD lesions. Before intervention, prevalence of active DD lesions fluctuated, whereas after intervention, prevalence of active DD lesions remained stable (Figure $3)$. In addition, 8 of the 9 herds had routine partialherd trims ( 25 to $45 \%$ of lactating cows were trimmed) every $<3$ mo. Therefore, before the study, a large proportion of the herd was being inspected and topically treated on a regular basis. Regardless, most herds had a high prevalence of active DD lesions at the start of the trial. In addition, although all farmers purported to have an individual treatment protocol in place and despite the high prevalence of active DD lesions, only 10 cows were treated topically throughout the study period. Thus, due to low frequency of individual treatments performed by farmers, this factor was not further analyzed. Although topical treatments cannot be ruled out as a possible confounder, strong evidence suggests 
that decreased prevalence of active DD lesions on farms with high baseline prevalence can be attributed to implementation of the standardized footbath protocol rather than topical treatments. Regardless, a follow-up period $>12$ wk would have enabled better understanding of the long-term effects of this intervention.

The great variation in footbath design and practices reported in the farms before the installation of the automatic footbath was not surprising, given the paucity of research on effective footbath protocols (Laven and Logue, 2006; Cook et al., 2012; Relun et al., 2013c). Guidance on footbathing practices remains quite empirical, as farmers seem to adopt advice from other farmers through word of mouth communication rather than from animal health advisers, thereby increasing variability in management practices (Relun et al., 2013c). Perhaps our descriptive results on some of the farms' original footbath protocol were inaccurate as authors relied on the farmers' answers about their protocol. For example, most farmers estimated the amount of chemical used, resulting in a potential under- or overestimation of the concentration used.

Poor leg cleanliness was associated with higher prevalence of active DD lesions; however, this association was confounded by farm, presumably because farms with a high prevalence of active DD lesions had a high prevalence of dirty legs. This association highlighted the importance of hygiene to limit DD prevalence. It is generally accepted that poor hygiene is a risk factor for DD (Potterton et al., 2012), and leg hygiene is commonly used as a measure to determine footbathing frequency (Cook, 2006). However, few studies have used direct measures of cleanliness in association with the risk of DD (Relun et al., 2012, 2013b). In agreement

Table 5. Final repeated measures multilevel logistic regression model for active digital (DD) dermatitis lesions (M2, M4.1) detected in the milking parlor before and after intervention with a standardized footbath protocol on 9 dairy farms $(\mathrm{n}=3,956 \text { feet })^{1}$

\begin{tabular}{|c|c|c|c|c|}
\hline Variable & Coefficient & Odds ratio & $95 \% \mathrm{CI}$ & $P$-value \\
\hline Intercept & -3.28 & & & \\
\hline \multicolumn{5}{|l|}{ Week of trial } \\
\hline 0 (baseline) & Referent & & & \\
\hline 2 & -0.41 & 0.66 & 0.40 to 1.11 & 0.122 \\
\hline 4 & -1.25 & 0.29 & 0.16 to 0.51 & $<0.001$ \\
\hline 6 & -0.78 & 0.46 & 0.27 to 0.79 & 0.004 \\
\hline 8 & -1.11 & 0.33 & 0.19 to 0.57 & $<0.001$ \\
\hline 10 (intervention) & -0.89 & 0.41 & 0.24 to 0.69 & 0.001 \\
\hline 12 & -0.51 & 0.60 & 0.36 to 0.99 & 0.047 \\
\hline 14 & -1.27 & 0.28 & 0.16 to 0.49 & $<0.001$ \\
\hline 16 & -1.94 & 0.14 & 0.08 to 0.27 & $<0.001$ \\
\hline 18 & -1.27 & 0.28 & 0.16 to 0.49 & $<0.001$ \\
\hline 20 & -1.33 & 0.26 & 0.15 to 0.47 & $<0.001$ \\
\hline 22 (end) & -0.57 & 0.57 & 0.34 to 0.95 & 0.030 \\
\hline \multicolumn{5}{|c|}{ Baseline herd prevalence of active DD lesions } \\
\hline Low $(<15 \%)$ & Referent & & & \\
\hline $\operatorname{High}(\geq 15 \%)$ & 0.47 & 1.60 & 0.85 to 3.02 & 0.145 \\
\hline \multicolumn{5}{|c|}{ Week of trial $\times$ baseline herd prevalence } \\
\hline 0 (baseline), low & Referent & & & \\
\hline 2, high & -0.36 & 0.70 & 0.39 to 1.24 & 0.224 \\
\hline 4, high & 0.46 & 1.60 & 0.85 to 2.99 & 0.143 \\
\hline 6 , high & 0.77 & 2.15 & 1.20 to 3.84 & 0.010 \\
\hline 8 , high & -0.17 & 0.84 & 0.46 to 1.56 & 0.585 \\
\hline 10 (intervention), high & 0.25 & 1.28 & 0.72 to 2.29 & 0.400 \\
\hline 12 , high & -2.03 & 0.13 & 0.07 to 0.24 & $<0.001$ \\
\hline 14 , high & -2.01 & 0.13 & 0.07 to 0.26 & $<0.001$ \\
\hline 16 , high & -1.63 & 0.19 & 0.09 to 0.41 & $<0.001$ \\
\hline 18 , high & -1.60 & 0.20 & 0.10 to 0.39 & $<0.001$ \\
\hline 20 , high & -1.37 & 0.25 & 0.13 to 0.49 & $<0.001$ \\
\hline 22 (end), high & -1.51 & 0.22 & 0.12 to 0.40 & $<0.001$ \\
\hline \multicolumn{5}{|l|}{ Parity } \\
\hline 1 & Referent & & & \\
\hline 2 & -0.10 & 0.91 & 0.70 to 1.17 & 0.451 \\
\hline$\geq 3$ & -0.28 & 0.75 & 0.58 to 0.98 & 0.035 \\
\hline \multicolumn{5}{|l|}{ Leg $^{-}$cleanliness ${ }^{2}$} \\
\hline Clean & Referent & & & \\
\hline Dirty & 0.24 & 1.27 & 1.03 to 1.56 & 0.027 \\
\hline
\end{tabular}

${ }^{1}$ Farm was forced into the final regression model as a fixed effect and cow as a random effect.

${ }^{2}$ Cleanliness scored on lateral lower hind legs, from the coronary band to the middle of the tarsal joint. Clean $=$ area partially covered with fresh manure; dirty $=$ dried caked manure for $\geq 50 \%$ of the area. 
with Relun et al. (2013b), it was noteworthy that leg cleanliness and DD status were recorded on the same day; consequently, hygiene status when DD lesions developed was unknown. Still, leg cleanliness can reflect environmental hygiene close to the time of DD scoring. We inferred that leg cleanliness can be used as a proxy of environmental hygiene.

Most research on footbathing protocols has been conducted on experimental dairy farms (Holzhauer et al., 2008; Speijers et al., 2010, 2012), with limited sample sizes (Teixeira et al., 2010; Holzhauer et al., 2012; Smith et al., 2014), or with relatively short follow-up periods (Silva et al., 2005; Thomsen et al., 2008; Smith et al., 2014). Only one large-scale study in France, conducted on 52 commercial farms ( $\mathrm{n}=4,677$ cows) and for a long interval (6 mo), assessed the effectiveness of various DD preventive regimens under different environments and management (Relun et al., 2012). However, intervals between DD inspections were relatively long (4 wk), perhaps allowing feet to undergo more than one transition of DD stages between observations (Nielsen et al., 2012). Nevertheless, this French study demonstrated that conducting intervention studies on several farms with different characteristics may improve reliability of results.

In the present study, a short (2-wk) interval between DD inspections was selected to decrease the possibility of missing transitions between DD stages (Nielsen et al., 2012). Lifting the cow's foot for inspection is the most accurate method for inspection of DD lesions; however,

(a)

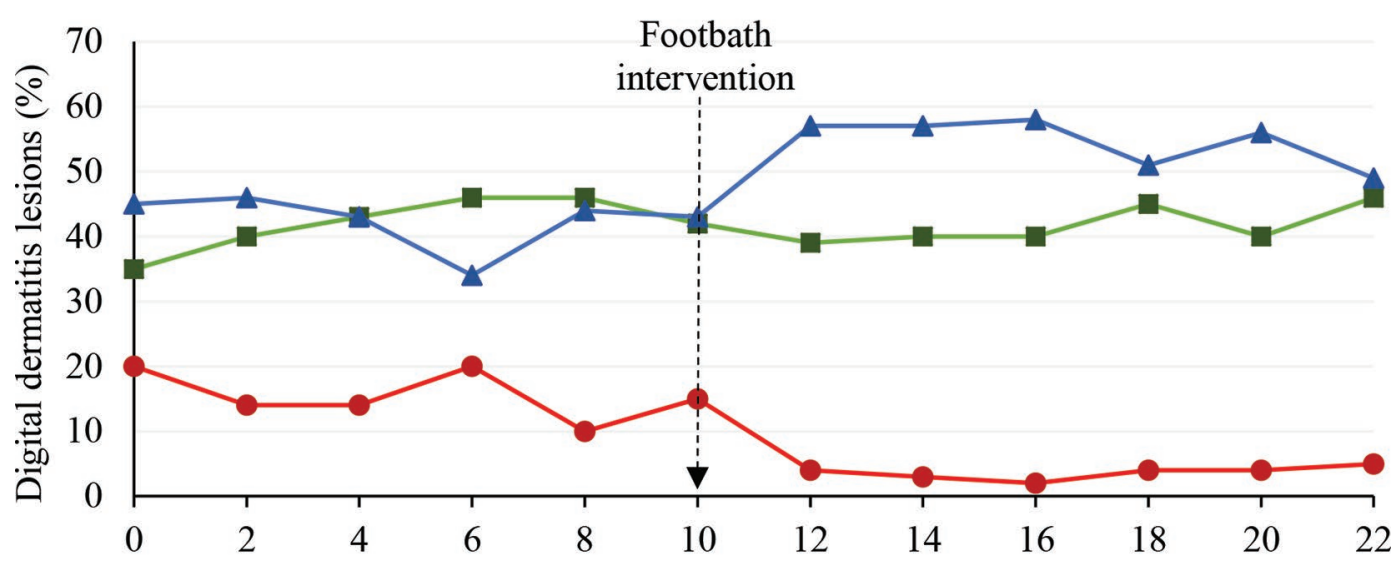

(b)

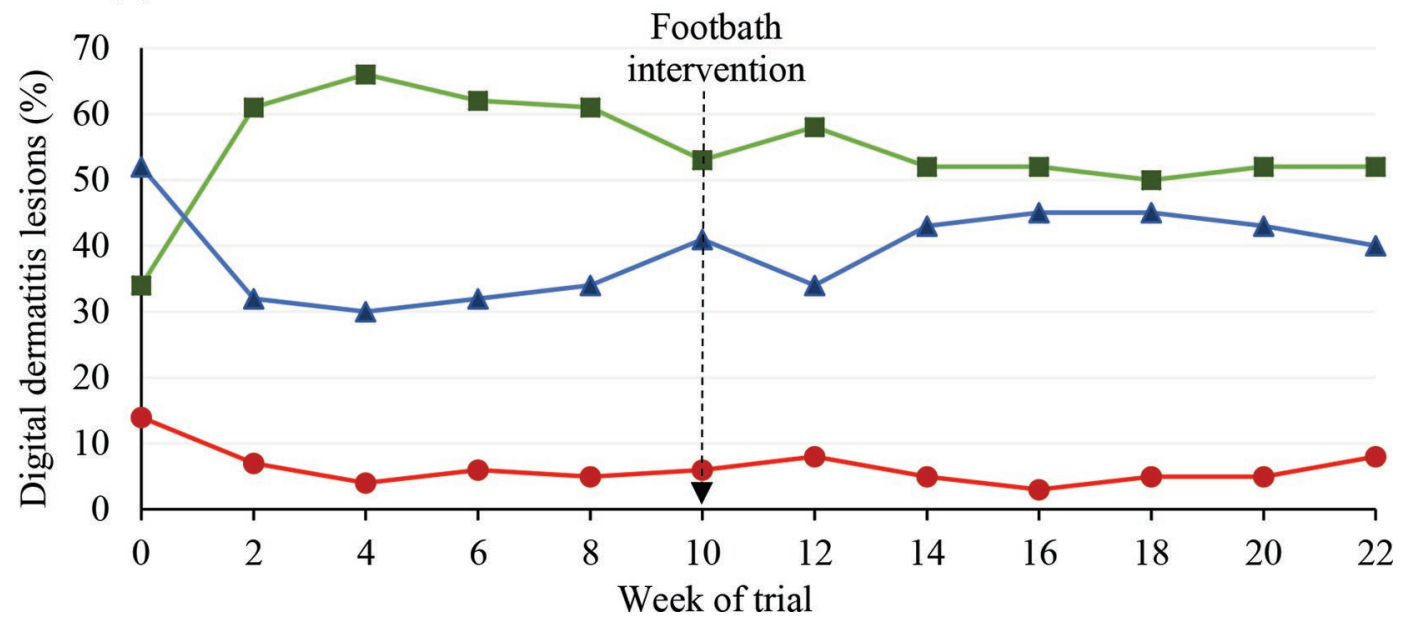

Figure 3. Percentage of feet $(\mathrm{n}=3,956)$ with various M-stages of digital dermatitis (Berry et al., 2012) before and after intervention with a standardized footbath protocol for (a) farms $(\mathrm{n}=6 ; \mathrm{n}=2,974$ feet) with high $(\geq 15 \%)$ within-herd prevalence of active digital dermatitis lesions (M2, M4.1) at baseline, and (b) farms $(\mathrm{n}=3 ; \mathrm{n}=982$ feet) with low $(<15 \%)$ within-herd prevalence of active digital dermatitis lesions at baseline. Color version available online. 
it is not a practical method that can easily be done on a regular basis. Therefore, a simple and effective method for DD inspection was used in the milking parlor with the assistance of a mirror (glued to a kitchen spatula), as previously described and validated (Solano et al., 2017). Inspection of feet in the milking parlor was adequately reliable to detect presence of DD lesions and for routine monitoring; however, this method was not sufficiently reliable to replace thorough foot inspection and definitive identification of M-stages in the trimming chute. Accuracy varied among M-stages, resulting in different percentages between milking parlor and trimming chute inspections. Milking parlor inspection of DD lesions was not sufficiently reliable to detect M1 or M4.1 lesions. Additionally, the authors were aware that lesions occurring in the interdigital space were not detected. For these reasons, trimming chute inspections were conducted at 3 key time points to increase accuracy and provide definite identification of M-stages. It was encouraging to detect a similar trend in prevalence of active DD lesions between milking parlor and trimming chute inspections, and a notably higher prevalence of feet without DD lesions at the end of the trial. Thus, effectiveness of the intervention was captured with both DD inspection methods.

Components of the standardized footbath protocol implemented in this study were reported to successfully control DD in field trials, and as a whole, it was selected after careful consideration of numerous protocols described in literature (Laven and Logue, 2006; Potterton et al., 2012). The implemented protocol included several changes to the farms' original protocol, namely the frequency and interval of use, the chemical's concentration, the footbath's design, and automation. Despite clear evidence that the implemented standardized protocol was effective, it is not possible to determine which factor had the largest effect on preventing active DD lesions because they were not tested independently. Therefore, we attributed the effectiveness of our protocol to the combination of all management changes.

To our knowledge, this was the first study to demonstrate the efficacy of automated footbaths. The aim of footbath automation was to eliminate human error, to consistently achieve a correct chemical concentration, and to ensure accurate frequency of use, emptying, and refilling. Despite the widespread use of footbaths and their demonstrated efficacy (Laven and Logue, 2006), footbathing is a costly measure mostly due to labor costs (Bruijnis et al., 2013). Hence, although automated footbath systems can initially be expensive, they can be cost-effective as they remove most of the labor. In addition, the benefits of ensuring consistent and accurate footbath protocols can result in decreased DD prevalence, and consequently lower costs related to hoof trimming, topical treatments and a high welfare benefit. The study findings on lack of compliance from farmers with other management practices after footbath intervention (i.e., clean cows' feet with water before footbath, topical treatments) highlighted the challenges of implementing measures that require labor effort or routine adjustment. To encourage farmers to adopt and maintain new strategies, these must be easy to implement and benefits must be readily apparent (Bruijnis et al., 2013; Relun et al., 2013c).

The selected farms were a convenient sample, possibly affecting DD prevalence estimates, although probably not results of the intervention. Potential bias introduced by not blinding observers was controlled by the intensive training program and mid-way check, which contributed to achievement of high interobserver agreement (Solano et al., 2017).

In the present study, farms served as their own control rather than a comparison with a subgroup of negative control farms. Being aware of potential bias introduced by the lack of a negative control group, the authors assessed the possible benefits and risks with the proposed study design. In that regard, potential bias introduced by seasonality was tested in advance, by analyzing electronic hoof health records on 87,834 cows collected by hoof trimmers from 2009 to 2012 through the Alberta Dairy Hoof Health Project (Solano et al., 2016). Results indicated fluctuation of DD prevalence throughout the year; however, no clear decrease or increase of DD prevalence in specific months was present that would suggest seasonal confounding. In addition, detection of spontaneous recovery resulting from individual or environmental factors would have been difficult without a negative control group. Therefore, the length of the baseline (pre-intervention) period was the same as the postintervention period and all observations preintervention were included in the statistical analyses to adjust for the baseline level (Dohoo et al., 2009). With this in mind, it was decided to allocate farms as their own control for 3 reasons: (1) include a larger sample of farms with an intervention, thus enhancing the power of the study; (2) minimize confounding from differences in herd characteristic due to wide variation in management practices across farms; and (3) encourage farmers to participate, knowing that an intervention would be applied on their farms if they enrolled.

\section{CONCLUSIONS}

Implementation of a proper footbath design and improvement of footbath management through standardization of a protocol based on scientific literature decreased prevalence of active DD lesions and increased prevalence of feet without DD lesions. The footbath 
design entailed an automated footbath that measured $3 \mathrm{~m}$ long, $0.25 \mathrm{~m}$ wide, $0.15 \mathrm{~m}$ high, with a weekly footbath protocol using $5 \% \mathrm{CuSO}_{4}$ for 4 consecutive milkings, replaced at a maximum of 200 cow passes. Effectiveness of the footbath intervention was evident on farms with high prevalence of active DD lesions at baseline, but not on farms that already had low prevalence; therefore, we concluded that following sciencebased recommendations on footbathing practices was effective. In addition, improving cow cleanliness would further result in control of active DD lesions.

\section{ACKNOWLEDGMENTS}

The authors thank participating farmers for their willingness, time, and financial contributions. We are especially grateful for cooperation of hoof trimmers Elbert Koster and Rob Geier, and for contributions of Ilse Geurts (Wageningen University, the Netherlands), Mart Wolbers, Fokke Sikkema (Utrecht University, the Netherlands), and Miranda Marchand (University of British Columbia, Canada) in data collection. We thank Dörte Döpfer (University of Wisconsin-Madison, Madison, WI) for her contributions in study design and delivery of workshops during this study and John Kastelic (Department of Production Animal Health, University of Calgary, AB, Canada) for editing this manuscript. We also thank Layne van Rhijn, Warren Winkelaar, and staff of Chinook Dairy Service (Lethbridge, AB, Canada) for their outstanding work with footbath construction, installation, and service; Silke Von Dyck from Dragonhyde Putty (T-Hexx Animal Health, Branchburg, NJ) for supporting our collaborative hoof trimmers; and Silvia Solano (independent consultant architect, San José, Costa Rica) for contributing the footbath schematic. This study was funded by Alberta Milk (Edmonton, AB, Canada), the Alberta Livestock and Meat Agency (Edmonton, AB, Canada), and Growing Forward 2 Biosecurity Funding (AB, Canada).

\section{REFERENCES}

Berry, S. L., D. H. Read, T. R. Famula, A. Mongini, and D. Döpfer. 2012. Long-term observations on the dynamics of bovine digital dermatitis lesions on a California dairy after topical treatment with lincomycin $\mathrm{HCl}$. Vet. J. 193:654-658.

Blowey, R. 2005. Factors associated with lameness in dairy cattle. In Pract. 27:154-162.

Bruijnis, M. R. N., B. Beerda, H. Hogeveen, and E. N. Stassen. 2012. Assessing the welfare impact of foot disorders in dairy cattle by a modeling approach. Animal 6:962-970.

Bruijnis, M. R. N., H. Hogeveen, and E. N. Stassen. 2010. Assessing economic consequences of foot disorders in dairy cattle using a dynamic stochastic simulation model. J. Dairy Sci. 93:2419-2432.
Bruijnis, M. R. N., H. Hogeveen, and E. N. Stassen. 2013. Measures to improve dairy cow foot health: consequences for farmer income and dairy cow welfare. Animal 7:167-175.

Cha, E. J. A. Hertl, D. Bar, and Y. T. Grohn. 2010. The cost of different types of lameness in dairy cows calculated by dynamic programming. Prev. Vet. Med. 97:1-8.

Cheli, R., and C. Mortellaro. 1974. La dermatite digitale del bovino. Pages 208-213 in Proc. 8th Intern. Conf. Dis. Cattle, Piacenza, Milan, Italy.

Chesterton, R. N., K. E. Lawrence, and R. A. Laven. 2008. A descriptive analysis of the foot lesions identified during veterinary treatment for lameness on dairy farms in north Taranaki. N. Z. Vet. J. $56: 130-138$.

Cook, N. B. 2006. Footbath alternatives. Accessed Oct. 4, 2016 http://www.vetmed.wisc.edu/dms/fapm/fapmtools/6lame/ Footbath_Alternatives.pdf.

Cook, N. B., J. Rieman, A. Gomez, and K. Burgi. 2012. Observations on the design and use of footbaths for the control of infectious hoof disease in dairy cattle. Vet. J. 193:669-673.

Cramer, G., K. D. Lissemore, C. L. Guard, K. E. Leslie, and D. F. Kelton. 2008. Herd- and cow-level prevalence of foot lesions in Ontario dairy cattle. J. Dairy Sci. 91:3888-3895.

Dohoo, I., W. Martin, and H. Stryhn. 2009. Veterinary Epidemiologic Research. 2nd ed. VER Inc., Charlottetown, Prince Edward Island, Canada.

Döpfer, D. 2009. The dynamics of digital dermatitis in dairy cattle and the manageable state of disease. Pages 1-5 in Proc. CanWest Veterinary Conference, Banff, AB, Canada.

Döpfer, D., K. Anklam, D. Mikheil, and P. Ladell. 2012c. Growth curves and morphology of three Treponema subtypes isolated from digital dermatitis in cattle. Vet. J. 193:685-693.

Döpfer, D., M. Holzhauer, and M. v. Boven. 2012a. The dynamics of digital dermatitis in populations of dairy cattle: Model-based estimates of transition rates and implications for control. Vet. J. 193:648-653.

Döpfer, D., M. Holzhauer, and M. van Boven. 2012b. The dynamics of digital dermatitis in populations of dairy cattle: Model-based estimates of transition rates and implications for control. Vet. J. 193:648-653.

Döpfer, D., A. A. H. M. ter Huurne, J. L. Cornelisse, A. J. A. M. van Asten, A. Koopmans, F. A. Meijer, Y. H. Schukken, I. Szakáll, W. Klee, and R. B. Bosma. 1997. Histological and bacteriological evaluation of digital dermatitis in cattle, with special reference to spirochaetes and Campylobacter faecalis. Vet. Rec. 140:620-623.

Ettema, J., S. Ostergaard, and A. R. Kristensen. 2010. Modelling the economic impact of three lameness causing diseases using herd and cow level evidence. Prev. Vet. Med. 95:64-73.

Fjeldaas, T., M. Knappe-Poindecker, K. E. Bøe, and R. B. Larssen. 2014. Water footbath, automatic flushing, and disinfection to improve the health of bovine feet. J. Dairy Sci. 97:2835-2846.

Gomez, A., K. S. Anklam, N. B. Cook, J. Rieman, K. A. Dunbar, K. E. Cooley, M. T. Socha, and D. Döpfer. 2014. Immune response against Treponema spp. and ELISA detection of digital dermatitis. J. Dairy Sci. 97:4864-4875.

Gomez, A., N. B. Cook, N. D. Bernardoni, J. Rieman, A. F. Dusick, R. Hartshorn, M. T. Socha, D. H. Read, and D. Döpfer. 2012. An experimental infection model to induce digital dermatitis infection in cattle. J. Dairy Sci. 95:1821-1830.

Gomez, A., N. B. Cook, J. Rieman, K. A. Dunbar, K. E. Cooley, M. T. Socha, and D. Döpfer. 2015. The effect of digital dermatitis on hoof conformation. J. Dairy Sci. 98:927-936.

Holzhauer, M., C. J. Bartels, C. Bergsten, M. M. J. van Riet, K. Frankena, and T. J. G. M. Lam. 2012. The effect of an acidified, ionized copper sulphate solution on digital dermatitis in dairy cows. Vet. J. 193:659-663.

Holzhauer, M., C. J. Bartels, M. van Barneveld, C. Vulders, and T. Lam. 2011. Curative effect of topical treatment of digital dermatitis with a gel containing activated copper and zinc chelate. Vet. Rec. 169:555. 
Holzhauer, M., D. Döpfer, J. de Boer, and G. van Schaik. 2008. Effects of different intervention strategies on the incidence of papillomatous digital dermatitis in dairy cows. Vet. Rec. 162:41-46.

Krull, A. C., V. L. Cooper, J. W. Coatney, J. K. Shearer, P. J. Gorden, and P. J. Plummer. 2016. A highly effective protocol for the rapid and consistent induction of digital dermatitis in Holstein calves. PLoS One 11:e0154481.

Laven, R. A., and D. N. Logue. 2006. Treatment strategies for digital dermatitis for the UK. Vet. J. 171:79-88.

Logue, D. N., T. Gibert, T. Parkin, S. Thomson, and D. J. Taylor. 2012. A field evaluation of a footbathing solution for the control of digital dermatitis in cattle. Vet. J. 193:664-668.

Nielsen, B. H., P. T. Thomsen, L. E. Green, and J. Kaler. 2012. A study of the dynamics of digital dermatitis in 742 lactating dairy cows. Prev. Vet. Med. 104:44-52.

Nuss, K. 2006. Footbaths: The solution to digital dermatitis? Vet. J. 171:11-13.

Potterton, S. L., N. J. Bell, H. R. Whay, E. A. Berry, O. C. D. Atkinson, R. S. Dean, D. C. J. Main, and J. N. Huxley. 2012. A descriptive review of the peer and non-peer reviewed literature on the treatment and prevention of foot lameness in cattle published between 2000 and 2011. Vet. J. 193:612-616.

Read, D. H., and R. L. Walker. 1998. Papillomatous digital dermatitis (footwarts) in California dairy cattle: Clinical and gross pathologic findings. J. Vet. Diagn. Invest. 10:67-76.

Relun, A., R. Guatteo, M. M. Auzanneau, and N. Bareille. 2013c. Farmers' practices, motivators and barriers for adoption of treatments of digital dermatitis in dairy farms. Animal 7:1542-1550.

Relun, A., R. Guatteo, P. Roussel, and N. Bareille. 2011. A simple method to score digital dermatitis in dairy cows in the milking parlor. J. Dairy Sci. 94:5424-5434.

Relun, A., A. Lehebel, N. Bareille, and R. Guatteo. 2012. Effectiveness of different regimens of a collective topical treatment using a solution of copper and zinc chelates in the cure of digital dermatitis in dairy farms under field conditions. J. Dairy Sci. 95:3722-3735.

Relun, A., A. Lehebel, M. Bruggink, N. Bareille, and R. Guatteo. 2013 b. Estimation of the relative impact of treatment and herd management practices on prevention of digital dermatitis in French dairy herds. Prev. Vet. Med. 110:558-562.

Relun, A., A. Lehebel, A. Chesnin, R. Guatteo, and N. Bareille. 2013a. Association between digital dermatitis lesions and test-day milk yield of Holstein cows from 41 French dairy farms. J. Dairy Sci. 96:2190-2200.

Rodríguez-Lainz, A., D. W. Hird, T. E. Carpenter, and D. H. Read. 1996. Case-control study of papillomatous digital dermatitis in Southern California dairy farms. Prev. Vet. Med. 28:117-131.

Scholey, R. A., W. E. R. Ollier, R. W. Blowey, R. D. Murray, and S. D. Carter. 2010. Determining host genetic susceptibility or resistance to bovine digital dermatitis in cattle. Adv. Anim. Biosci. 1:2.

Shearer, J., and S. Van Amstel. 2013. Manual of Foot Care in Cattle. 2nd ed. Hoard's Dairyman, Fort Atkinson, WI.

Silva, L. A. F., C. A. Silva, J. R. J. Borges, M. C. S. Fioravanti, G. T. Borges, and I. B. Atayde. 2005. A clinical trial to assess the use of sodium hypochlorite and oxytetracycline on the healing of digital dermatitis lesions in cattle. Can. Vet. J. 46:345-348.

Smith, A. C., C. L. Wood, K. J. McQuerry, and J. M. Bewley. 2014. Effect of a tea tree oil and organic acid footbath solution on digital dermatitis in dairy cows. J. Dairy Sci. 97:2498-2501.

Solano, L., H. W. Barkema, C. Jacobs, and K. Orsel. 2017. Validation of the M-stage scoring system for digital dermatitis on dairy cows in the milking parlor. J. Dairy Sci. 100:1592-1603. https://doi. org/10.3168/jds.2016-11365.

Solano, L., H. W. Barkema, S. Mason, E. A. Pajor, S. J. LeBlanc, and K. Orsel. 2016. Prevalence and distribution of foot lesions in dairy cattle in Alberta, Canada. J. Dairy Sci. 99:6828-6841.

Solano, L., H. W. Barkema, E. A. Pajor, S. Mason, S. J. LeBlanc, J. C. Zaffino Heyerhoff, C. G. R. Nash, D. B. Haley, E. Vasseur, D. Pellerin, J. Rushen, A. M. de Passillé, and K. Orsel. 2015. Prevalence of lameness and associated risk factors in Canadian HolsteinFriesian cows housed in freestall barns. J. Dairy Sci. 98:6978-6991.

Solano, L., H. W. Barkema, E. A. Pajor, S. Mason, and K. Orsel. 2013 Decreasing lameness and increasing cow comfort on Alberta dairy farms. Pages 297-306 in Proc. WCDS Advances in Dairy Technology, Red Deer, AB, Canada.

Somers, J. G., K. Frankena, E. N. Noordhuizen-Stassen, and J. H. M. Metz. 2003. Prevalence of claw disorders in Dutch dairy cows exposed to several floor systems. J. Dairy Sci. 86:2082-2093.

Speijers, M. H., G. A. Finney, J. McBride, S. Watson, D. N. Logue, and N. E. O'Connell. 2012. Effectiveness of different footbathing frequencies using copper sulfate in the control of digital dermatitis in dairy cows. J. Dairy Sci. 95:2955-2964.

Speijers, M. H. M., L. G. Baird, G. A. Finney, J. McBride, D. J. Kilpatrick, D. N. Logue, and N. E. O'Connell. 2010. Effectiveness of different footbath solutions in the treatment of digital dermatitis in dairy cows. J. Dairy Sci. 93:5782-5791.

Tadich, N., E. Flor, and L. Green. 2010. Associations between hoof lesions and locomotion score in 1098 unsound dairy cows. Vet. J. 184:60-65.

Teixeira, A. G. V., V. S. Machado, L. S. Caixeta, R. V. Pereira, and R. C. Bicalho. 2010. Efficacy of formalin, copper sulfate, and a commercial footbath product in the control of digital dermatitis. J. Dairy Sci. 93:3628-3634.

Thomsen, P. T., J. T. Sorensen, and A. K. Ersboll. 2008. Evaluation of three commercial hoof-care products used in footbaths in Danish dairy herds. J. Dairy Sci. 91:1361-1365.

USDA. 2009. Dairy 2007, Part IV: Reference of dairy cattle health and management practices in the United States. USDA:APHIS:VS CEAH. Fort Collins, CO. \#N494.0209. Accessed Oct. 4, 2016 https://www.aphis.usda.gov/animal_health/nahms/dairy / downloads/dairy07/Dairy07_dr_PartIV.pdf.

Zinpro International Bovine Lameness Committee. 2014. Cattle lameness: Identification, prevention and control of claw lesions. 1st ed. Zinpro Corporation, Eden Prairie, MN. 